\title{
Cancer prevention: a question of priorities
}

Ernst L. Wynder of the American Health Foundation argues for the virtues of preventive medicine in combating cancer

RECENTLY, two independent studies have considered the relative contribution of environmental factors to the incidence of cancer*. Their common conclusion was that cancer is not an inevitable consequence of living, and that most cancers appear to be related to life-style factors. Estimates on the contribution of lifestyle to cancer incidence generally parallel each other (see below). The unanswered question is how we should react to our failure to curb those environmental factors that cause the continued high risk for many cancers.

As long ago as 1950, epidemiologic evidence established the causative association between oigarette smoking and lung cancer. Twenty-seven years later, tobacco usage still accounts for more than one-third of all male cancer deaths in the United States, in Britain and in other countries. Little did we expect that man's illusion of immortality would foster public apathy toward health messages related to smoking; nor did we foresee the unwillingness and inability of the medical establishment to assist significantly the motivation of the public to modify health behaviour. The opposition of commercial and agricultural interest, of course, was to be expected.

With the impact of these countervailing forces now so recognisable, the measure of success of a preventionoriented approach to health maintenance seems to be inversely proportional to the responsibility one must assume for one's behaviour. It is thus far easier to launch a campaign directed against occupational and iatrogenic cancers than it is to infringe upon personal behaviour since, with the former, one can marshal the energy of government, the media and unions. It is no wonder that Doll regards the efforts necessary to solve the problem of nutrition-related cancers as an even more difficult task.

* Doll, R., Nature 265, 589-596; Wynder, E. L. and Gori, G. B., J. Natn. Cancer Inst. 58, 825-832.
The identification and subsequent reduction of environmentally induced cancers requires a multidisciplinary undertaking, ranging from molecular biology to public health. Just as Comprehensive Clinical Cancer Centres can more effectively prescribe treatment regimens for cancer patients, a multi-faceted approach to environmental cancers would provide a vehicle for researchers to work in tandem on issues related to environmental cancers. The creation of Interdisciplinary Centres for Cancer Prevention is now called for.

The cross-fertilisation between epidemiologists, biologists, chemists and public health professionals has already proved constructive in focusing, directing and applying research efforts. For these efforts to succeed, however, the broad support of our academic and government institutions, and especially of the scientific community, is required.

Endeavours in the field of prevention are currently receiving only a fraction of available government or private funding, with the possible exception of investigations on industrial carcinogens. Economic considerations may force a change. As disease care costs continue to rise, prevention will necessarily attract greater attention to avoid bankrupting the existing medical care delivery system.

It has been said that those who do not learn from history are condemned to relive it. The lessons to be learned from scurvy, smallpox and cholera can be repeated for most cancers, as well as for other chronic conditions. Eradication of a disease is not dependent upon fully comprehending the disease mechanism. This applies to cancer prevention as well.

The question remains whether we will accept these lessons from history, particularly when personal and societal 'sacrifices' are demanded. A patient dying from a self-inflicted cancer would, in retrospect, certainly answer with an unqualified "yes." But what of the rest of us looking toward the future? The development and support of Interdisciplinary Centres for Cancer Prevention could help us reach the proper perspective on the values of preventive medicine. It could also draw us closer to the day when what we know to be avoidable disease will no longer plague the health and economic fibres of ours and future generations.

PERCENT OF CANCER INCIDENCE ATTRIBUTABLE TO SPECIFIC ENVIRONMENTAL FACTORS - USA

PREVENTIVE POTENTIAL

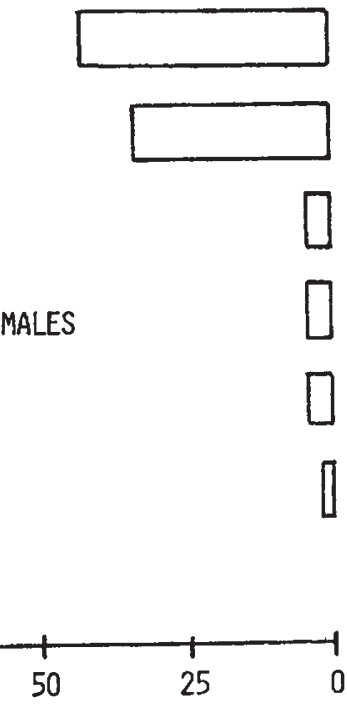

TOTAL

PREVENTIVE POTENTIAL

DIET

TOBACCO

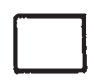

RADIATION

(UV \& X-RAY)

DRUGS

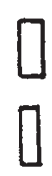

FEMALES

OCCUPATION

ALCOHOL

(PLUS TOBACCO)

EXOGENOUS

HORMONES
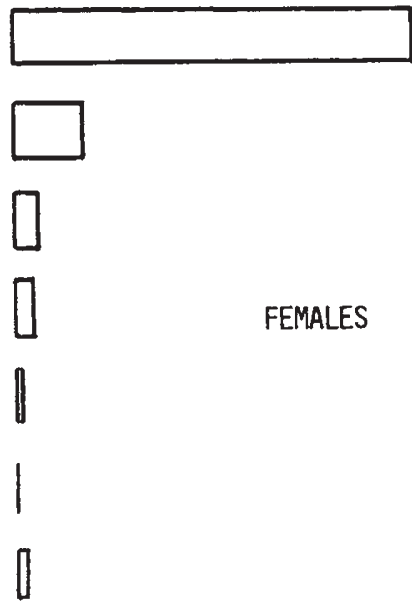

PERCENT
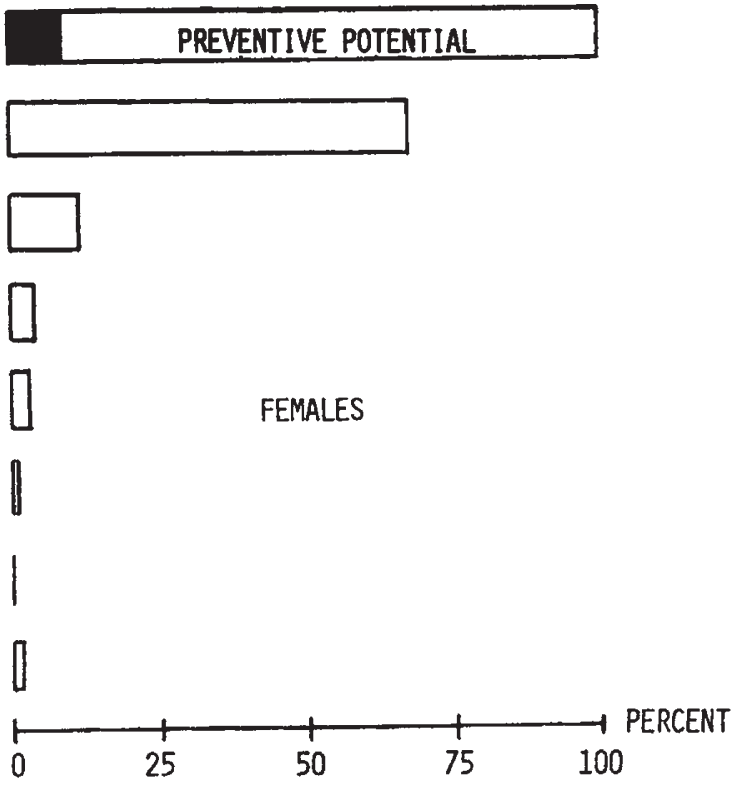